\title{
Slow release morphine did not reduce neonatal abstinence syndrome more than methadone
}

\section{Fischer G, Jagsch R, Eder H, et al. Comparison of methadone and slow-release morphine maintenance in pregnant addicts. Addiction 1999 Feb;94:231-9.}

\section{Question}

In pregnant women who are opioid dependent or polysubstance abusers, does slow release morphine (SRM) with an intermediate half life $(16 \mathrm{~h})$ reduce neonatal abstinence syndrome (NAS) in their newborn infants more than methadone?

\section{Design}

Randomised, unblinded, controlled trial with a \{mean follow up of 15 weeks $\}^{*}$.

\section{Setting}

A drug addiction outpatient clinic at a university hospital in Vienna, Austria.

\section{Patients}

48 pregnant women (mean age $26 \mathrm{y}$, mean gestation 22 wks) who were dependent on opioids or abused polysubstances (mean duration $61 \mathrm{mo}$ ) and were willing to follow the maintenance programme and avoid using illegal drugs. Follow up was complete.

\section{Intervention}

Women were allocated to oral SRM tablets given twice daily $(n=24)$ or an oral methadone solution given once daily $(n=24)$. A flexible dose regimen was used, and the mean dose at delivery was $53 \mathrm{mg}$ for methadone and $300 \mathrm{mg}$ for SRM. All women received psychosocial counselling twice weekly and group psychotherapy once weekly.

\section{Main outcome measures}

NAS was assessed every 6 hours using the Finngegan score. Other outcomes were illegal drug consumption (assessed by urinanalysis and new injection sites), nicotine dependence (Fagerström questionnaire), and fetal distress.

\begin{abstract}
Main results
Neonatal infants born to mothers in the methadone and SRM groups did not differ for duration of NAS (16 d in the methadone group $v 21 \mathrm{~d}$ in the SRM group, $\mathrm{p}=0.18$ ). Mothers' mean daily dose of SRM or methadone was not associated with duration of NAS $(r=0.53, \mathrm{p}=0.20$ for methadone; $r=0.39, \mathrm{p}=0.34$ for SRM). More women in the methadone group than in the SRM group used additional opiates $(\mathrm{p}<0.05)$ (table) and benzodiazepines $(\mathrm{p}<0.05)$. Nicotine dependence at delivery decreased from baseline levels in both groups (mean score difference 11.7, $\mathrm{p}=0.02$ for methadone and $16.1, \mathrm{p}=0.02$ for $\mathrm{SRM}$ ). All women, except 1 woman who had amniotic rupture, delivered during the last trimester (mean gestation 38 wks); no other gynaecological problems occurred. All children were healthy.
\end{abstract}

\section{Conclusions}

In pregnant women who were dependent on opiates or who abused polysubstances, slow release morphine (SRM) of intermediate length half life did not reduce neonatal abstinence syndrome more than methadone did. Women who received SRM used fewer additional opiates and benzodiazepines than women who received methadone. All children were born healthy.

*Follow up information supplied by author.

Slow release morphine (SRM) v methadone in pregnant women who were opiate dependent'

Outcome SRM Methadone RRR $(95 \%$ CI $) \quad$ NNT (CI)

\begin{tabular}{lllll}
\hline Used additional opiates & $21 \%$ & $50 \%$ & $58 \%(6$ to 83$)$ & $4(2$ to 54$)$
\end{tabular}

†Abbreviations defined in glossary. RRR, NNT, and CI calculated from data in article. Mean follow up was 15 weeks (information supplied by author).

Source of funding: Mayor of Vienna (Fonds zur Förderung der wissenschaftlicher Forschung).

For correspondence: Dr G Fischer, Drug Addiction Outpatient Clinic, Department of General Psychiatry, University Hospital of Vienna, Währinger Gürtel 18-20, 1090 Vienna, Austria. Fax +43 1404003500 .

\section{Commentary}

Drug addiction during pregnancy affects both mother and child and is a growing public health concern. A recent survey in the US showed that $5 \%$ of pregnant women used illegal drugs. ${ }^{1}$ Despite the gravity of the problem, few empirical data exist to guide clinical management.

Heroin dependence in pregnancy is a clinical challenge. On the one hand, pregnancy presents a unique opportunity in that the mother may be eager to stop her drug use for fear that damage will be inflicted on her unborn baby. On the other hand, the fetus is as dependent as the mother on heroin. Because the immature fetal nervous system is particularly sensitive to drug withdrawal, maintaining the fetus and mother on a stable level of opiates is preferable to in-utero detoxification. Opioid maintenance treatment during pregnancy, however, only postpones the withdrawal reaction. After delivery, the neonate is still at risk for the detrimental effects of abstinence syndrome.

To overcome this no-win situation, a method that detoxifies pregnant women without causing substantial distress to the fetuses is needed. Alternatively, we may search for an opiate that causes fewer or milder episodes of NAS than methadone, which is currently the most commonly prescribed opiate substitute for pregnant women.

Fischer et al have taken the second approach, but found that SRM of intermediate length half life $(16 \mathrm{~h})$ was not better than methadone for reducing the duration and severity of NAS. These results are perhaps not surprising given that the morphine preparation chosen has a shorter half life than methadone (about $24 \mathrm{~h}$ ). Had an SRM preparation with a long half life been used, the results might have been different.

Nevertheless, this study shows that SRM is superior to methadone for reducing harm. Fewer participants in the SRM group than in the methadone group had additional benzodiazepine or opiates injection. Hence, the next logical step would be to test whether SRM preparations of long half life are better than methadone for reducing NAS while maintaining superiority in harm reduction.

Dominic T S Lee, MB, ChB, MRCPsych The Chinese University of Hong Kong Shatin, New Territories, Hong Kong

1 Westat Inc. National pregnancy and health survey: drug use among women delivering livebirths, 1992. Rockville, MD: National Institute of Drug Abuse, 1996. 